\title{
Framework for Part Families Associated with Setup Sequence Based Similarity in Reconfigurable Manufacturing System / Cellular Manufacturing System
}

\author{
Muhammad Ali, Aamer Baqai, Sajid Ullah Butt, and Syed Maaz Hasan
}

\begin{abstract}
The configurations of reconfigurable manufacturing system (RMS) evolved around market requirements and corresponding manufacture capabilities, exploiting all available resources. Similar products / parts families are grouped together and requires a specific manufacturing configuration in term of setups and respective tools changes in RMS. The recognition of minimum number of setup changes in multi parts production and its application for part family formation is an important step in RMS. In the present work, a novel method has been developed for recognition of minimum number of part setups with tool change options for calculation of similarity relation of parts, keeping in view the precedence constraints, machining constraints and good manufacturing practices. Bypass moves and idle machines in setup sequencing (BMIMS) similarity coefficient based on setup sequence of parts has been developed on the basis of Longest common subsequence (LCS) for setup sequences. The developed coefficient of similarity was compared for analysis with the existing similarity/distance coefficients, already available in literature. The average linkage clustering algorithm has been applied for classification of example parts using this similarity coefficient. The developed methodology is useful for RMS as well as for cellular manufacturing system.
\end{abstract}

Index Terms-Reconfigurable manufacturing system, part family formation, feature grouping, setup sequence, similarity coefficient.

\section{INTRODUCTION}

Reconfigurable manufacturing system (RMS) has evolved significantly over the decades. For production of a product family, RMS requires changes in hardware and software structures. In RMS, parts / products are grouped together in families on the basis of similarities. In case of products, similarities are based in terms of common parts, and for parts it is in terms of common manufacturing operations. The effectiveness of RMS depends upon recognition of parts/products families which contribute towards maximum utilization of system and productivity. System is configured for production of one part family at a time catering for its operational requirements and requires reconfiguration for the production of next part family. Therefore, finding appropriate

Manuscript received October 20, 2016; revised January 10, 2017.

The authors are with the Department of Mechanical Engineering, College of Electrical \& Mechanical Engineering (CEME), National University of Science and Technology (NUST) Islamabad, Pakistan (e-mail: muhammad.ali80@me.ceme.edu.pk, aamer.baqai@ceme.nust.edu.pk, sajidullahbutt@ceme.nust.edu.pk,maaz.hassan@ceme.nust.edu.pk). part family is the core requirement of designing a RMS and group technology (GT) is used to accomplish this task.

RMS is built for a part family and immediately reconfigured later for next part family in turn due to rapid market requirements Koren et al. and Xiaobo et al. [1]-[3]. Abdi and Labib [4] identified product family which were based on quantitative and qualitative aspects of products along with operational similarities. Galan et al. [5] has adopted an approach based on product modularity, compatibility, commonality, reusability and product demand for product family formation. Kashkoush [6] used product assembly sequence tree, parts commonality in the product and its demand similarity coefficients for product family formation. Abdi and Labib et al., Galan et al., and Rakesh et al. [4]- [7] has considered only jaccard similarity coefficient and neglected operation precedence. Goyal et al., Choobineh et al., Tam et al., and Irani and Huang et al. [8]- [11] used operation sequence based similarity coefficients to develop part families. Goyal [8] has considered not only operation sequence but also developed BMIM (bypass moves and idle machines) similarity coefficient which determines minimum bypass movement and idle machines during part flow.

In order to take the advantage of minimum setups for maximum of operations to achieve better accuracy and tolerance, BMIMS (bypass moves and idle machines in setup) similarity coefficient has been developed. BMIMS similarity coefficient uses tool change option for completion of maximum operations in a setup to avoid frequent changes of setups.

\section{REVIEW OF EXISTING APPROACHES BASED ON OPERATION SEQUENCE}

Developed similarity coefficients are based on operation sequence and sequence of machines in a part flow process. Compliant index, LCS (longest common subsequence), merger coefficient, modified merger coefficient and BMIM (bypass move and idle machines) similarity coefficients are developed between two operation sequence strings. Summary of developed techniques for part family formation are shown in Table I.

\section{Proposed Methodology}

Operation sequence based similarity coefficients is used for calculation of similarity coefficients as discussed above, whereas proposed methodology for part family formation is based on setup sequencing similarity coefficient which includes operation sequence. The methodology will focus on 
identification of feature groups, number of setups, selection of datum, operation sequence within a setup, setup sequence and similarity coefficient for parts. Flow chart of methodology is shown in Fig. 1. Assumptions of auto tool changer with each machine, milling operation on milling machines only and each setup require a separate machine to perform operations are taken into consideration for proposed methodology.

TABLE I: SUMMARY OF TECHNIQUES FOR FART FAMILY FORMATION

\begin{tabular}{|c|c|c|c|}
\hline Author & \multicolumn{3}{|c|}{$\begin{array}{l}\text { Techniques for part family formation } \\
\end{array}$} \\
\hline Ho (1993) & Compliant index based similarity coefficient [12] & $C O_{x y}=\frac{\left(C F_{x}+C B_{x}\right)}{2 * N_{x}}$ & \\
\hline $\begin{array}{l}\text { Askin and } \\
\text { Zhou (1998) }\end{array}$ & $\begin{array}{l}\text { LCS (longest common subsequence) based } \\
\text { similarity coefficient [13] }\end{array}$ & $S_{x y}=\max \left\{\frac{\left|L C S_{x y}\right|}{|x|}, \frac{\left|L C S_{x y}\right|}{|y|}\right\}$ & \\
\hline $\begin{array}{l}\text { Irani and } \\
\text { Huang } \\
(2000)\end{array}$ & $\begin{array}{l}\text { Merger similarity coefficient based on LCS } \\
\text { having substitutions, insertion and deletion of } \\
\text { operations [11] }\end{array}$ & $m c_{(x, y)}=\max \left[1-\frac{m d_{(x, y)}+\frac{i d_{(x, y)}}{|x|}}{|y|+1}\right]$ & If $|x|>|y|$ \\
\hline $\begin{array}{l}\text { Huang } \\
(2003)\end{array}$ & Modified merger coefficient [14] & $m c_{(x, y)}=\max \left[1-\frac{m d_{x y}+\frac{i d(y, x)}{O_{\max }}+\frac{|x|+|y|}{O_{\max }^{2}}}{|y|}, 0\right.$ & If $|x|>|y|$ \\
\hline Goyal (2013) & $\begin{array}{l}\text { BMIM (bypass moves and idle machines) } \\
\text { similarity coefficient is based on LCS (longest } \\
\text { common subsequence) [8] }\end{array}$ & $S_{x y}=1-\left\{\left[\frac{B P M_{x}}{2 *\left|T M_{x}\right|}+\frac{B P M_{y}}{2 *\left|T M_{y}\right|}\right]+\right.$ & $\left.\left.\frac{I M_{x}}{*\left|S C S_{x y}\right|}+\frac{I M_{y}}{2 *\left|S C S_{x y}\right|}\right]\right\}$ \\
\hline
\end{tabular}

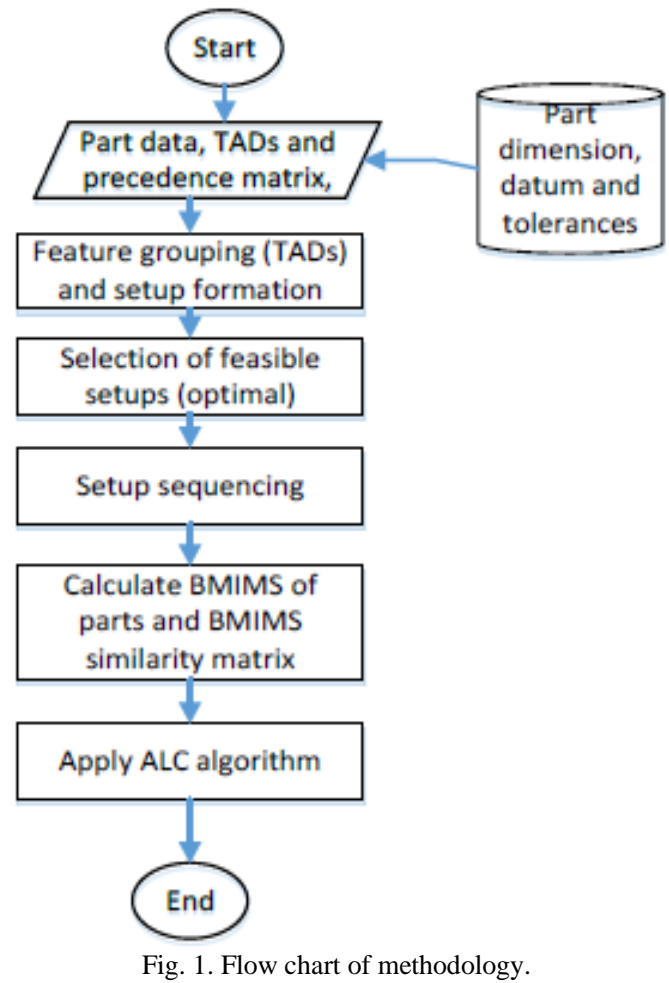

Part containing the machining features represents the geometric specifications of a part. Machining of features in a setup, without setup change or repositioning of part, are grouped together and known as feature grouping. Machining the maximum of features in a minimum setups ensure better tolerance during manufacturing [15]. Feature grouping is based on TADs of feature, feature geometry \& precedence and topological interaction relation among features. Primarily grouping is based on TADs of features. TAD feature group is formed on basis of features having common $\mathrm{TAD}$, whereas features having multiple TADs are assigned to different TAD feature groups. Most of features machining in a single setup, tolerances and setup fixtures are factors to assign single TAD for a feature having multiple TADs.

To explain the method, a four features component has been taken. Operation data of example part is shown in Table II and Fig. 2. All six faces of prismatic block are rough machined. P1 is planner surface obtained by milling operation and TAD for this operation is from all directions less $+\mathrm{Z}$. Through hole $\mathrm{A} 1$ has $\mathrm{TAD}+\mathrm{Z}$ and $-\mathrm{Z}, \mathrm{A} 2$ hole has $\mathrm{TAD}+\mathrm{X}$ and $-\mathrm{X}$. Chamfering operation can only be performed from $-\mathrm{Z}$ direction. To machine this part common TAD are $(+X$ or $-X)$ and $(-Z)$.

TABLE II: OPERATION DATA OF EXAMPLE PART

\begin{tabular}{|l|l|c|c|c|}
\hline Feature & Description & Op & Op No & \multicolumn{1}{c|}{ TAD } \\
\hline P1 & Planner Surface & $\mathrm{M}$ & 1 & $+\mathrm{X},-\mathrm{X},+\mathrm{Y},-\mathrm{Y},-\mathrm{Z}$ \\
\hline \multirow{3}{*}{ A1 } & \multirow{3}{*}{ Through Hole } & $\mathrm{D}$ & 2 & $+\mathrm{Z},-\mathrm{Z}$ \\
\cline { 3 - 5 } & & $\mathrm{R}$ & 3 & $+\mathrm{Z},-\mathrm{Z}$ \\
\cline { 3 - 5 } & \multirow{2}{*}{ Through Hole } & $\mathrm{B}$ & 4 & $+\mathrm{Z},-\mathrm{Z}$ \\
\cline { 3 - 5 } & & $\mathrm{R}$ & 5 & $+\mathrm{X},-\mathrm{X}$ \\
\hline \multirow{2}{*}{$\mathrm{C}$} & Chamfer & $\mathrm{C}$ & 7 & $-\mathrm{Z}$ \\
\hline
\end{tabular}

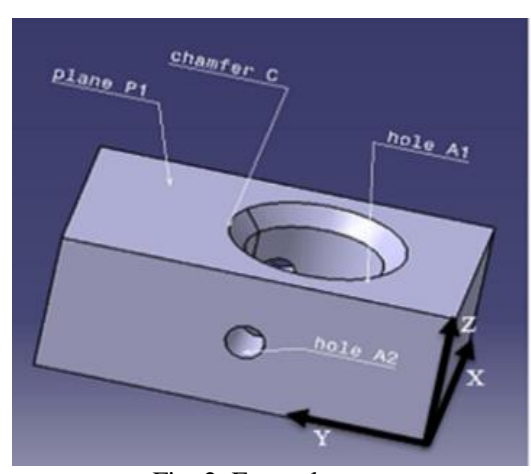

Fig. 2. Example part.

Common TADs features are grouped together for setup formation. Importance is accorded to machine capability to access direction for machining a feature. Properly identified datum is important for achieving the specified accuracy / tolerance of the feature. It acts as a theoretical exact point, line, area, surface or axis which is used during machining processes as an origin for dimension measurement. Datum features form datum planes i.e. primary, secondary and tertiary datum planes which are perpendicular to each other [15].

Setup grouping is based on a number of features which are machined in same setups [16]. Machining operation sequencing within the setup depends upon precedence constraints, machining constraints and good manufacturing practices. Minimum tool change is an important criterion for machining operation sequencing and can be achieved by 
grouping similar operations together such as group drilling operations without violating precedence constraints.

Setup sequencing is done in a similar way as the sequencing machining operations within the setups. Precedence relations among features of different setups are the prime criteria for setup sequencing. Setup with greater number of features should be considered at last (without violating precedence constraints). If done earlier, it may raise issues like instability of part or less clamping area for remaining setups. In the same manner, features having larger dimensions or sizes preferably be machined in the last to avoid above mentioned problems.

Keeping in view the precedence constraints and good manufacturing practice, number of setups obtained for example part are three and setup sequence is $\{(1),(5,6)$, $(2,3,7,4)\}$ and corresponding TADs are $\{(-Z),(+X$ or $-X)$, $(-Z)\}$. In a similar manner grouping of features, setups and machining operation sequences within each setup and setup sequencing is done for the second part. Algorithm for proposed methodology is shown in Fig. 3.

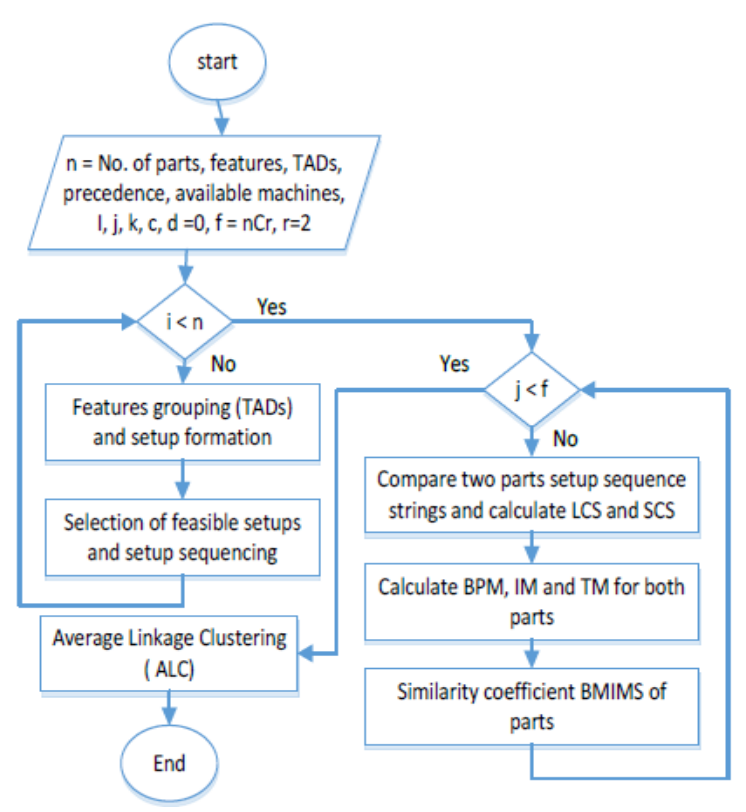

Fig. 3. Algorithm for proposed methodology.

\section{A. Development of BMIMS (Bypass Moves and Idle Machines in Setups) Symmetry Coefficient}

Operations sequence based similarity coefficients has been used in cellular manufacturing. So far no similarity coefficient has been developed based on setups sequence. Setup sequencing symmetry will ensure smooth flow of material as well as achievement of better dimensional tolerances. Most of dimensional tolerance errors are outcome of repeated changing of setups. Completion of machining in minimum number of setups will ensure reduction of tolerance errors. This will also ensure time reduction factor as maximum time is consumed for the preparation of proper setup (clamping and fixtures) as compared to tool changing.

Methodology for finding BMIMS uses similar parameters as of Goyal BMIM similarity coefficient [8] but having changes of setup sequence instead of operation sequence. Goyal BMIM symmetry coefficient is calculated for two parts operation sequence whereas BMIMS similarity coefficient is based on two parts setup sequence. List of longest common setups in both setup sequence is used for finding the LCS, following the precedence constraints. Similar operations do not require following the exact operation sequence in both setups but operations will be performed with tool change options. The shortest common supersequence (SCS) is the shortest possible length of a sequence that can accommodate all setup sequences without violating precedence constraints. It can be obtained from LCS of both setup sequences.

Ratio of tools required and operations for each setup is added in main equation (8) for calculation of similarity coefficient. In case of same setup sequence for two parts, the difference of tools required and operations ratios for each setup will determine the similarity coefficient for said parts. The developed similarity coefficient BMIMS value become the same as Goyal similarity coefficient BMIM when it is considered that all operations in the sequence are having separate setups. The ratio of tools required and operations become one and average of setup also become one and whole equation becomes Goyal equation shown in Table I.

\section{B. Mathematical Model for Determining BMIMS Similarity}

This section introduces the formulation of the proposed mathematical model of BMIMS. The model parameters are:

$x, y \quad$ Setup sequence of part $x$ and part $y$

LCS $_{x y}$ Longest common subsequence between setup sequences $x$ and $y$

$\mathrm{SCS}_{x y}$ Shortest common supersequence between setup sequences $x$ and $y$

$\mathrm{NOBL}_{x}$ Number of setups of setup sequence $x$, appended before $\mathrm{LCS}_{x y}$ to form $\mathrm{SCS}_{x y}$

$\mathrm{NOAL}_{x}$ Number of setups of setup sequence $x$, appended after $\mathrm{LCS}_{x y}$ to form $\mathrm{SCS}_{x y}$

NOIL Number of setups of setup sequence $x$, appended in between $\mathrm{LCS} x y_{\text {to }}$ form $\mathrm{SCS}_{x y}$

$\xi_{x} \quad$ Number of bypass moves before $\operatorname{LCS}_{x y}$ while producing part $x$

$\varphi_{x} \quad$ Number of bypass moves after $\operatorname{LCS}_{x y}$ while producing part $x$

$T R_{x i} \quad$ Tool required in ith setup of part $x$ where $\mathrm{i}=1,2,3 \ldots n$

$O P_{x i} \quad$ Operations in ith setup of part $x$

$T R_{y j} \quad$ Tool required in $j$ th setup of part $y$ where $j=1,2,3 \ldots m$

$O P_{x j} \quad$ Operations in $j$ th setup of part $y$

The following equations are used to find bypass moves, idle machines, material handling moves and finally similarity coefficient of BMIMS.

$$
\begin{gathered}
\xi_{x}=\left\{\begin{array}{cc}
N O B L_{y} & \text { If }\left(N O B L_{y} \leq N O B L_{x}\right) \\
0, & \text { otherwise }
\end{array}\right. \\
\varphi_{x}=\left\{\begin{array}{cc}
N O A L_{y} & \text { If }\left(N O A L_{y} \leq N O A L_{x}\right) \\
0, & \text { otherwise }
\end{array}\right. \\
B P M_{x}=N O I L_{y}+\xi_{x}+\varphi_{x} \\
B P M_{y}=N O I L_{x}+\xi_{y}+\varphi_{y} \\
S C S_{x y}=|x|+|y|-L C S_{x y} \\
T M_{x}=B P M_{x}+|x|+1 \\
I M_{x}=\left|S C S_{x y}\right|-|x|
\end{gathered}
$$


$S_{x y}=1-\left\{\begin{array}{c}\left.\frac{1}{2 *|x|} \sum_{i=1}^{n} \frac{\left|T R_{x i}\right|}{\left|O P_{x i}\right|}\left[\frac{B P M_{x}}{\left|T M_{x}\right|}+\frac{I M_{x}}{\left|S C S_{x y}\right|}\right]+\frac{1}{2 *|y|} \sum_{j=1}^{m} \frac{\left|T R_{y j}\right|}{\left|O P_{y j}\right|} \mid \frac{B P M_{y}}{\left|T M_{y}\right|}+\frac{I M_{y}}{\left|S C S_{x y}\right|}\right] \\ +\left[\left|\frac{1}{|x|} \sum_{i=1}^{n} \frac{\left|T R_{x i}\right|}{\left|O P_{x i}\right|}-\frac{1}{|y|} \sum_{j=1}^{m} \frac{\left|T R_{y j}\right|}{O P_{y j}}\right|\right]\end{array}\right\}$

TABLE III: OPERATION DATA FOR PARTS

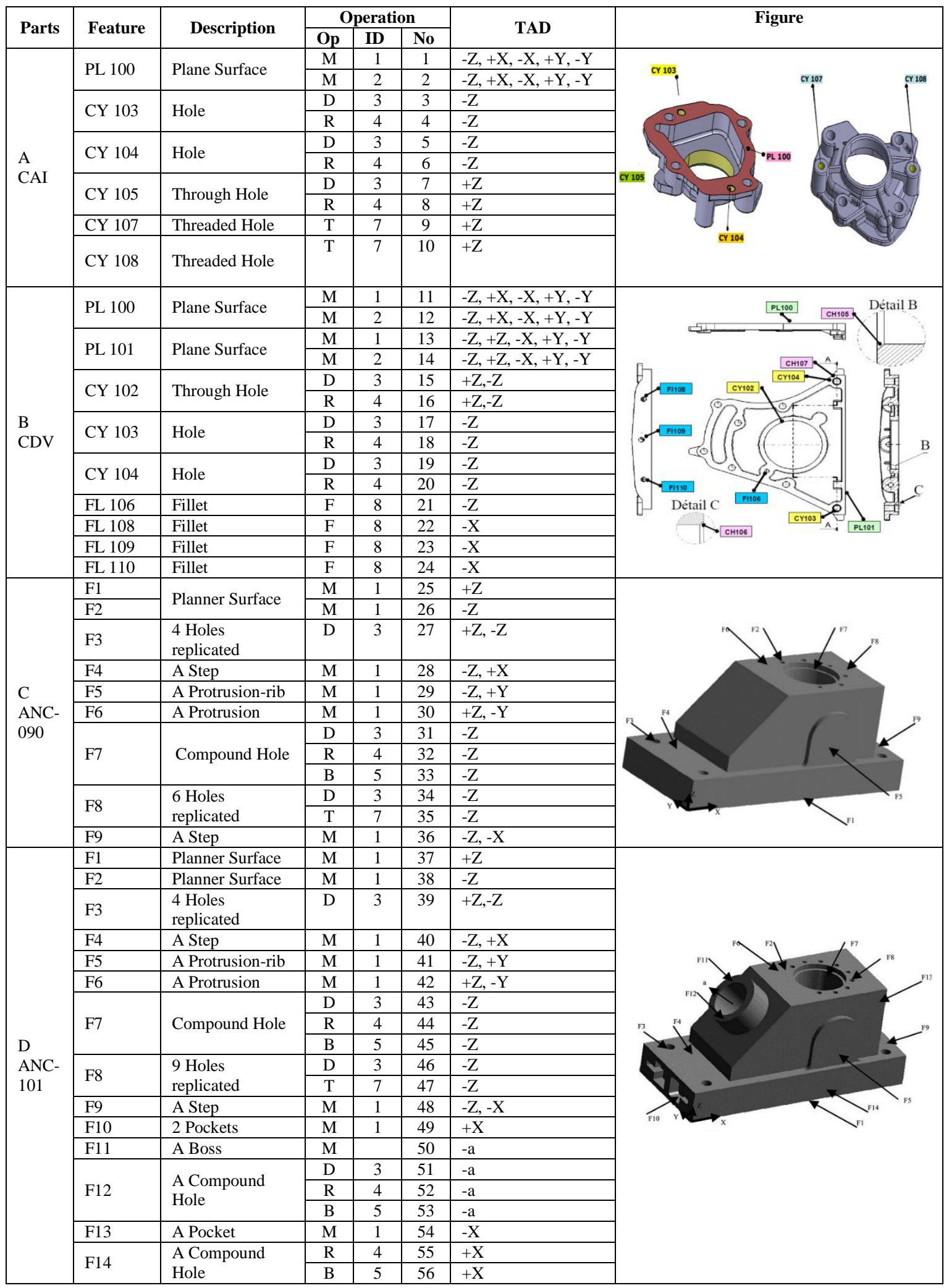

TABLE IV: COMPUTATIONAL ILLUSTRATION OF BMIMS SIMILARITY COEFFICIENT

\begin{tabular}{|llllll|}
\hline Part & & Setup1 & Setup2 & Setup3 & Setup4 \\
\hline \multirow{4}{*}{ CAI } & Op & M & D,D,R,R & B,B,T,T & \\
& Op ID & 1,2 & $3,3,4,4$ & $3,4,7,7$ & \\
& Op No & 1,2 & $3,4,5,6$ & $7,8,9,10$ & \\
& TAD & $-\mathrm{Z}$ & $-\mathrm{Z}$ & $+\mathrm{Z}$ & \\
\hline
\end{tabular}




\begin{tabular}{|c|c|c|c|c|c|c|c|}
\hline CDV & $\begin{array}{l}\text { Op } \\
\text { Op ID } \\
\text { Op No } \\
\text { TAD }\end{array}$ & $\begin{array}{l}\mathrm{M}, \mathrm{M} \\
1,2 \\
11,12 \\
-\mathrm{Z} \\
\end{array}$ & & $\begin{array}{l}\text { M,M } \\
1,2 \\
13,14 \\
-X \\
\end{array}$ & $\begin{array}{l}\mathrm{B}, \mathrm{R}, \mathrm{B}, \mathrm{R}, \mathrm{B}, \mathrm{R}, \mathrm{F} \\
3,4,3,4,3,4,8 \\
\begin{array}{c}15,16,17,18,19,20,21 \\
-\mathrm{Z}\end{array}\end{array}$ & & ,F 23,24 \\
\hline CAI & & 1,2 & & $3,4,3,4,3,4,8$ & $3,4,7,7$ & & Idle Machine \\
\hline CDV & 1,2 & 1,2 & & $3,4,3,4,3,4,8$ & 8,8, & & Bypass Move \\
\hline $\begin{array}{l}\mathrm{BPM}_{\mathrm{x}} \\
\mathrm{BPM}_{\mathrm{y}} \\
\mathrm{TC}_{\mathrm{O}} \mathrm{OP}_{\mathrm{x} 1}\end{array}$ & $\begin{array}{l}0 \\
1 \\
1 \\
\end{array}$ & $\begin{array}{c}\mathrm{IM}_{\mathrm{x}} \\
\mathrm{IM}_{\mathrm{y}} \\
\mathrm{TC} / \mathrm{OP}_{\mathrm{x} 2} \\
\end{array}$ & $\begin{array}{l}1 \\
1\end{array}$ & $\begin{array}{l}\mathrm{TM}_{\mathrm{x}} \\
\mathrm{TM} \\
0.5 \\
\end{array}$ & $\begin{array}{l}4 \\
6 \\
\mathrm{TC} / \mathrm{OP}_{\mathrm{x} 3} \\
\end{array}$ & $\mathrm{SCS}_{\mathrm{xy}}$ & 0.6638 \\
\hline
\end{tabular}

TABLE V: RESULTS OF EXISTING SIMILARITY / DISSIMILARITY COEFFICIENTS

\begin{tabular}{l|llllll}
\hline \multicolumn{1}{c|}{ Parts } & $\begin{array}{c}\text { Complaint } \\
\text { index }\end{array}$ & LCS & $\begin{array}{c}\text { Merger } \\
\text { Coefficient }\end{array}$ & $\begin{array}{c}\text { Modified Merger } \\
\text { Coefficient }\end{array}$ & $\begin{array}{c}\text { BMIM Similarity } \\
\text { Coefficient }\end{array}$ & $\begin{array}{c}\text { BMIMS Similarity } \\
\text { Coefficient }\end{array}$ \\
\hline CDV-CAI & 0.65 & $\underline{\mathbf{0 . 6}}$ & 0.7208 & 0.6908 & 0.4975 & 0.6639 \\
ANC090-CDV & 0.4583 & 0.5 & 0.5219 & 0.4813 & 0.473 & 0.6539 \\
ANC101-090 & 0.9167 & $\underline{\mathbf{1}}$ & $\underline{\mathbf{1}}$ & $\underline{\mathbf{0 . 9 9 8 3}}$ & 0.8 & 0.7276 \\
ANC090-CAI & $\underline{\mathbf{0 . 5}}$ & $\mathbf{0 . 6}$ & 0.6288 & 0.5903 & 0.5521 & 0.6203 \\
ANC101-CAI & 0.55 & $\underline{\mathbf{0 . 6}}$ & 0.7045 & 0.6725 & 0.3871 & 0.5174 \\
ANC101-CDV & $\underline{\mathbf{0 . 5}}$ & 0.5714 & 0.5833 & 0.5525 & 0.5046 & 0.5571 \\
\hline
\end{tabular}

\section{CASE STUdy}

For illustration of the developed approach, four parts i.e. CAI, CDV, ANC-090 and ANC-101 are considered to find out how much similarity do they have among each other (machining process similarity). Parts features along with respective TADs and parts are shown in Table III above. Setup sequence and operations sequence within each setup are generated through precedence matrix for each part [16]. Computational illustration of similarity coefficient i.e. BMIMS for Part CAI and part CDV is shown in Table IV above, which is $S_{x y}=0.6638$.

\section{RESUlts AND ANALYSIS}

The algorithm of BMIMS similarity coefficient prove to be useful in identifying part families similarities, which is based on the concept of applying LCS and SCS for setup sequence. Previously developed similarity coefficients have been used for comparing of results of current similarity index. The previously discussed work in literature review has not been taken into account setup sequencing, as they are based on operation sequencing. For comparison of result, similarity index of each method for four parts are calculated and results shown in Table $\mathrm{V}$ above.

Drawbacks / limitations of complaint index, LCS, merger coefficients and modified merger coefficients are highlighted in are shown in bold and underlined in the Table. Complaint index similarity coefficient is same i.e. 0.5 for parts (CAI\&ANC-090) and (CDV\&ANC-101). All four have different operations sequences and cannot have same value. Similarly, LCS similarity coefficient for parts groups (CAI\&CDV), (CAI\&ANC-090) and (CAI\&ANC-101) have same value of 0.6 , which also shows limitation of the approach. Merger coefficient and modified merger coefficient have shown almost $100 \%$ similarity between parts ANC-090 and ANC-101. Although parts are similar to some extent but $100 \%$ similarity is not possible as part ANC-101 have more operations than part ANC-090. Results of BMIM and BMIMS have variations but no two results are same. Fig. 4 shows clustering trends of different similarity coefficients.

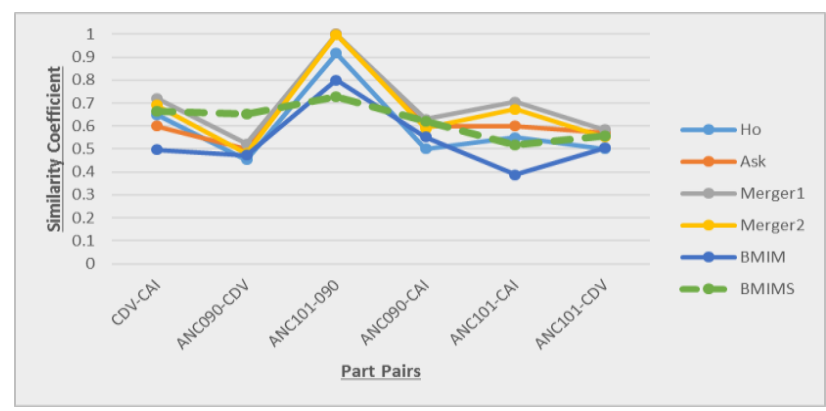

Fig. 4. Graphical representation of similarity coefficients.

Comparing the results of BMIM and BMIMS shows that BMIMS results have been improved gradually almost for all parts. Practically, if multiple operations can be performed in a setup by changing tools instead of single operation then result would definitely be improved and the same improvement of BMIMS results is evident. Only for parts ANC-101 and ANC-090 value is slightly on lower side, it is because of difference in precedence matrix of both parts which effected the setup formation and overall result of similarity coefficient.

BMIMS similarity coefficient of four parts can have same value as of BMIM similarity coefficient if all operation sequence of both parts are assumed as independent setup for each operation (not setup sequence).

Average linkage clustering (ALC) has been applied for classification of parts for BMIMS similarity index [17]. ALC methodology groups higher similarity coefficients between parts and can be calculated with following formula:

$$
S_{i j}=\frac{\sum_{m \in i} \sum_{n \in j} S_{m n}}{N_{i} \cdot N_{j}}
$$

To obtain the dendogram, the method is repeated till grouping of all parts into a family. As per BMIMS dendogram shown in Fig. 5, the similarity of all four parts for grouping is $59 \%$. Whereas the grouping percentage of BMIM similarity index for four parts is $48 \%$. This also shows improvement of results of BMIMS similarity coefficient for grouping of part families. 


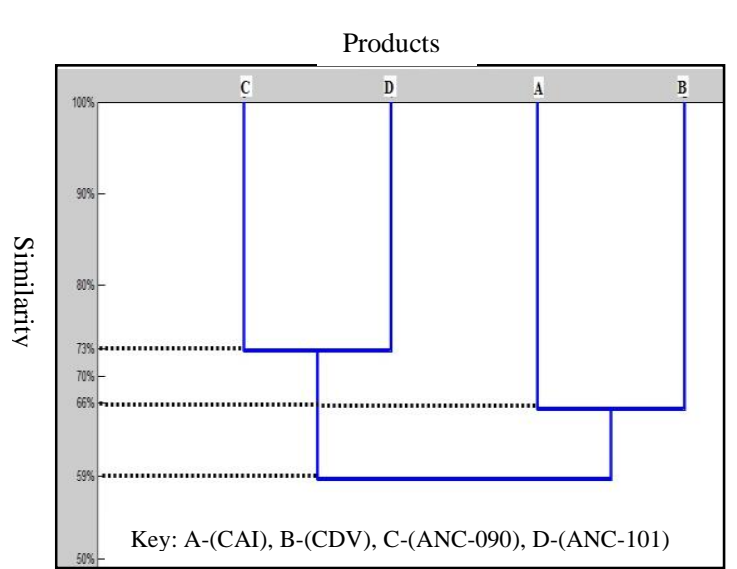

Fig. 5. Dendogram for BMIMS.

\section{CONCLUSION}

This research has presented an improved methodology of similarity coefficient for grouping the parts into families. The production efficiency and economy depend upon proper selection of part families in RMS. Selection of proper setups for part production resulting in lesser setups, thus improving accuracy and tolerances and also improving part similarity index for part family formation. BMIMS similarity coefficient is based on setup sequence, LCS and SCS concept and bypass moves and idle machines are calculated for each part setup sequence. Future work recommendations include the integration of operation time and machining tolerances in developing of part family for improvement of manufacturing quality.

\section{REFERENCES}

[1] Y. Koren, U. Heisel, F. Jovane, T. Moriwaki et al., "Reconfigurable manufacturing systems," CIRP Annals-Manufacturing Technology, vol. 48, pp. 527-540, 1999.

[2] Z. Xiaobo, W. Jiancai, and L. Zhenbi, "A stochastic model of a reconfigurable manufacturing system, framework," International Journal of Production Research, vol. 38, no. 10, pp. 2273-2285.

[3] Z. Xiaobo, J. Wang, and Z. Luo, "'A stochastic model of a reconfigurable manufacturing system.' Optimal configurations," International Journal of Production Research, vol. 38, no. 1, pp. 2829-2842, 2000b.

[4] M. R. Abdi and A. W. Labib, "Grouping and selecting products: The design key of Reconfigurable Manufacturing Systems (RMSs)," Int $J$ Prod Res, vol. 42, no. 3, pp. 521-546, 2004.

[5] R. Galan, "A systematic approach for product families formation in reconfigurable manufacturing systems," Robotics and Computer-Integrated Manufacturing, vol. 23, pp. 489-502, 2007.

[6] M. Kashkoush and H. ElMaraghy, "Product family formation for reconfigurable assembly systems," CIRP, 2014, pp. 302-307, vol. 17.

[7] K. Rakesh, "A framework for simultaneous recognition of part families and operation groups for driving a reconfigurable manufacturing system," Advances in Production Engineering \& Management Journal, vol. 5, pp. 45-58, 2010.

[8] K. K. Goyal, "A comprehensive approach to operation sequence similarity based part family formation in the reconfigurable manufacturing system," International Journal of Production Research, vol. 51, pp. 1762-1776, 2013.

[9] F. Choobineh, "A framework for the design of cellular manufacturing systems," International Journal of Production Research, vol. 26, pp. 1161-1172, 1988.

[10] K. Y. Tam, "An operation sequence based similarity coefficient for part families formations," Journal of Manufacturing Systems, vol. 9, pp. $55-68,1990$.

[11] S. A. Irani and H. Huang, "Custom design of facility layouts for multiproduct facilities using layout modules," IEEE Transactions on Robotics and Automation, vol. 16, no. 3, pp. 59-267, 2000.

[12] Y. C. Ho et al., "Two sequence-pattern, matching-based, flow analysis methods for multi-flow lines layout design," International Journal of Production Research, 1993.

[13] R. G. Askin and M. Zhou, "Formation of independent flow-line cells based on operation requirements and machine capabilities," IIE transactions, vol. 30, pp. 319-329, 1998.

[14] H. Huang, "Facility layout using layout modules," PhD Dissertation, Graduate School of the Ohio State University, 2003.

[15] M. Hazarika and U. S. Dixit, "Setup planning for machining," Springer Briefs in Manufacturing and Surface Engineering.

[16] A. Baqai, "Co-conception des processus d'usinage et des configurations cinematiques d'un systeme de production reconfigurable," 2010.

[17] H. Seifoddini and P. M. Wolfe, "Application of the similarity coefficient method in group technology" IIE Transaction, vol. 18, no. 3, pp. 271-277, 1986.

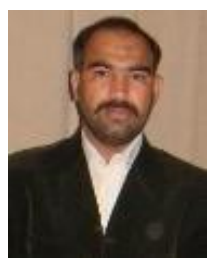

Muhammad Ali received the B.S. degree in mechanical engineering from National University of Science and Technology (NUST) Islamabad, Pakistan, Department of Mechanical Engineering, College of Electrical \& Mechanical Engineering (CEME) in 1999. Currently he is perusing MS degree in the field of design and manufacturing.

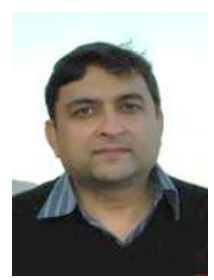

Aamer Baqai is Associate Professor at the National University of Science and Technology (NUST) Islamabad, Pakistan, Department of Mechanical Engineering, College of Electrical \& Mechanica Engineering (CEME).

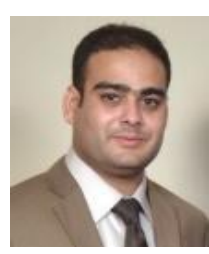

Sajid Ullah Butt is Assistant Professor with the National University of Science and Technology (NUST) Islamabad, Pakistan, Department of Mechanical Engineering, College of Electrical \& Mechanical Engineering (CEME).

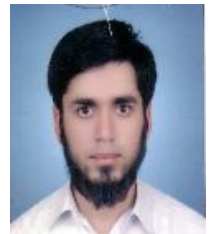

Syed Maaz Hasan received the B.S. degree in mechanical engineering from National University of Science and Technology (NUST) Islamabad, Pakistan, Department of Mechanical Engineering, College of Electrical \& Mechanical Engineering (CEME) in 2010. $\mathrm{He}$ is currently perusing his $\mathrm{PhD}$ degree in the field of design and manufacturing from NUST. 